\title{
Effectiveness of Measures Taken to Protect Waters by Example of Soda Production Plant in Inowrocław
}

\author{
Adam Gołub ${ }^{1, *}$, Janina Piekutin' \\ 1 BialystokTechnical University, Faculty of Civil and Environmental Engineering, ul.Wiejska 45A, 15-350 Białystok, \\ Poland \\ * Corresponding author's e-mail: a.golub@doktoranci.pb.edu.pl
}

\begin{abstract}
The "Soda Mątwy" plant in Inowrocław produces light and heavy soda ash by means of the Solvay method, and the production process is associated with the formation of highly saline waste, which can adversely affect all elements of the environment. In view of the existing threats, attempts are undertaken to limit the quantity and improve the quality of post-production sewage. The aim of the study is to determine the effectiveness of activities to protect the water in the area of the soda production plant in Inowrocław. The assessment of their effectiveness was based on the analysis of the current level of chloride concentration reduction at 4 measurement points around the plant and determination of the trend for further changes. In all piezometers, the concentration of chloride ions has decreased and showed the same tendency in subsequent years, which allows draw conclusions confirming high effectiveness of the activities related to water protection.
\end{abstract}

Keywords: soda ash; sludge treatment; water quality

\section{INTRODUCTION}

There are many industrial areas in the entire country that require reclamation. They constitute a large environmental and ecological threat, because of their storage, i.e. the most common method of waste disposal. Incorrect location and operation of landfills adversely affects all elements of the natural environment (air, plants, groundwater and surface waters, soils). The unsealed bottom of the landfill causes the leachates produced by infiltrating rainwater to penetrate through its subsoil and slopes, becoming a source of long-term pollution of soils and groundwater [Urbańska and Urbański 2012, Wiater 2011]. These leachates affect the receivers in a variety of ways. Some of the components contained in them adversely impact the hydrological conditions, whereas others impair water quality, have a destructive effect on biocenosis and inhibit the self-cleaning processes [Harat and Grmela 2008, Mosiej et al. 2007, Policht-Latawiec et al. 2013].
Therefore, emphasis should be put on limiting the amount of industrial wastewater produced by improving its quality (e.g. using pre-treatment at a given plant or in municipal wastewater treatment plants) and proper water management. The requirement of ensuring proper quality of industrial wastewater was included in the National Program for Municipal Wastewater Treatment [2017].

An example of a strong impact on natural waters includes the plants producing light and heavy soda ash, belonging to the chemical industry. The production of Solvay soda is related to the formation of saline waste [Matthews and Effler 2003, Şener 2008, Steinhauser 2008]. Such plants minimize the negative impact on the natural environment by pre-treating the post-production sewage and preventing their contact with underground and surface water.

This paper presents the diagnosis of groundwater contamination with chloride ions in the "Soda Mątwy" Production Plant in Inowrocław that is a producer of light and heavy soda ash. 
The aim of the analysis was to assess the effectiveness of measures limiting the impact of soda industry on the environment.

\section{RESEARCH OBJECT AND METHODS}

The Production Plant "Soda Mątwy" in Inowrocław is located within the catchment of the Eastern Noteć river and its tributary (Słony Rów) (Figure 1). The groundwater in the surroundings of the plant is fed from two sources: infiltration of rainwater and inflow from the northern part of Inowrocław. The groundwater flow in the western part of the plant takes place in the south-western direction, and in the south-east (Figure 1).

The post-production residues in the plant contain elevated concentrations various compounds of mainly carbonate, hydroxide and calcium sulfate, magnesium hydroxide and chloride as well as ammonium nitrogen [Matthews and Effler 2003, Şener 2008, Steinhauser 2008]. They are directed to the installation for the production of soda lime, where chlorides are leached out using fresh water. The sludge washed and dehydrated on filter presses, containing less than $3 \%$ of chlorides, is transferred for agricultural purposes. Meanwhile, the effluents are discharged to the sedimentary ponds (Figure 2), where their temperature is reduced, and mixing and precipitating the sediments by binding insoluble carbon dioxide from the air occur [Kasikowski et al. 2008, Siwiec et al. 2016]. The collected supernatant water is pumped into the Vistula River [Kasikowski et al. 2007].
In the past, all ponds shown in Figure 2 were used for storing the waste from production and the ashes from a combined heat and power plant. Their total area was over 110 ha. Due to the process of waste utilization from the production launched in 1992, the area of flooded ponds was reduced and the quality of sludge directed to them was improved. Currently, the landfill area in use is around 13 ha.

In order to protect the water, 3 drainage barriers were constructed as well (Figure 2): East (1 and A-I), West (J, K) and Central (L). These barriers, consisting of wells draining the underground water to pressure pipelines to the Vistula river, are aimed at capturing the contaminants that leaked from the area of ponds to groundwater and preventing them from spreading to the adjacent areas [Pietrucin and Czop 2015].

Water for the chloride concentration test, which is an indicator of water pollution around the plants involved in the production of soda ash [Effler and Matthews 2003], was taken from 4 piezometers filtered within the quaternary aquifer (markings 1-4 in Figure 2). The sampling was carried out in accordance with the PN-EN ISO 5667:2008 standard, with the frequency resulting from the plant environmental monitoring program.

For percent values of chloride concentration reduction at each measurement point, a 3-order polynomial trend line was determined along with its equation and the value of coefficient of determination $\mathrm{R}^{2}$ to determine the change tendencies.

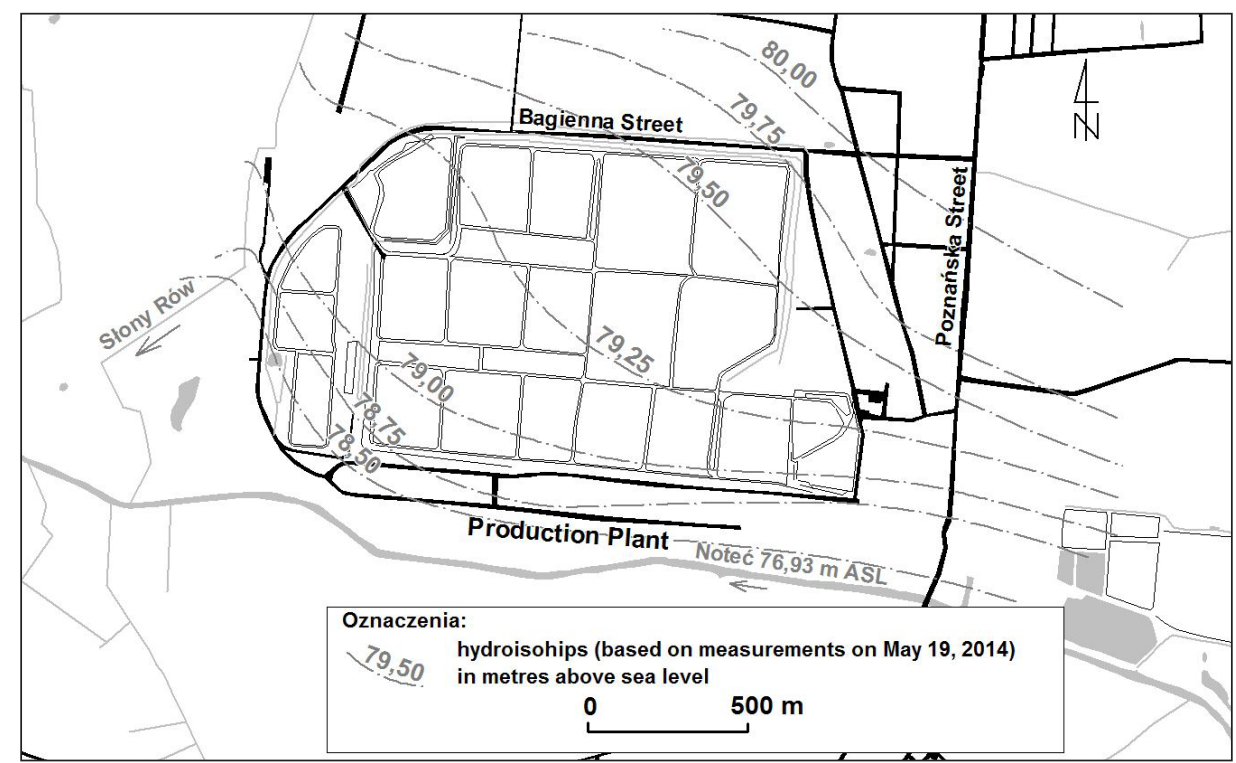

Figure 1. Location of the plant and map of hydroisohips of the Quaternary aquifer 


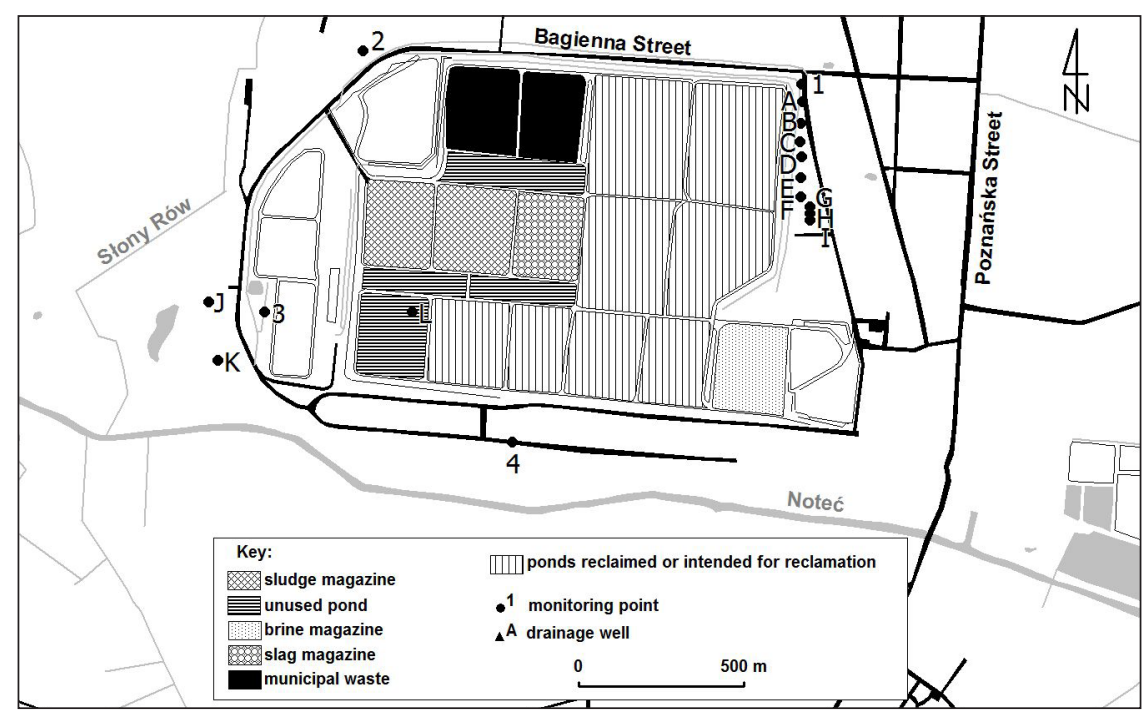

Figure 2. Location of sedimentary ponds, where the 1-4 are measuring points, 1 and A-L are drainage wells

\section{RESULTS AND DISCUSSION}

The calculated degrees of chloride ion decrease in individual piezometers over the whole research period, as shown in Figures 3-6. The degree of chloride ions reduction at monitoring point 1 (Figure 3) varies from 1.4 to almost $60 \%$. Over the past 25 years, a regular decline has been noticed and in the last period, about $50 \%$ reduction has been achieved. The well has been characterized by irregular work resulting from frequent clogging of the filter ever since it was constructed. An uneven inflow of saline water and drainage works associated with the reconstruction of the drainage barrier causes large fluctuations in the results between series of measurements. The obtained data suggest that the concentration of chloride ions will drop further in subsequent years. This is due to the trend of line and high $\mathrm{R}^{2}$ coefficient.
At point 2 (Figure 4), the reduction in the chloride concentration was very rapid, almost reaching $70 \%$ in the period from 1995 to 2000 . After 2000, however, it was not as intense anymore and amounted to another $20 \%$ between 2000 and 2017. During the entire measurement period in this piezometer, the chloride concentration decreased by over $90 \%$. Small variations in the results between the series are characteristic in this case. The coefficient of determination $\mathrm{R}^{2}=0.9766$ of the trend line indicates a further drop in the chloride concentration at this point.

At the measurement point 3 (Figure 5), the reduction in chloride concentration is very diverse, and variations between series is substantial. This may result from the varying intensity of pollutants leaching from the soil aeration zone in the area of sedimentary ponds. Therefore, various charges of chlorides reach the piezometer 3 , located on the

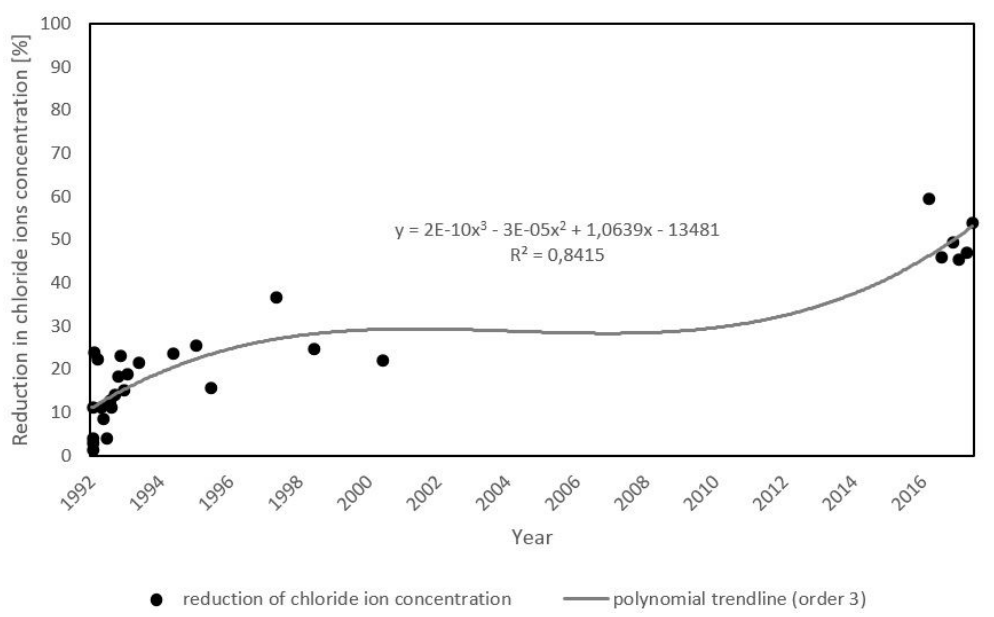

Figure 3. Reduction of chloride ion concentration at point 1 


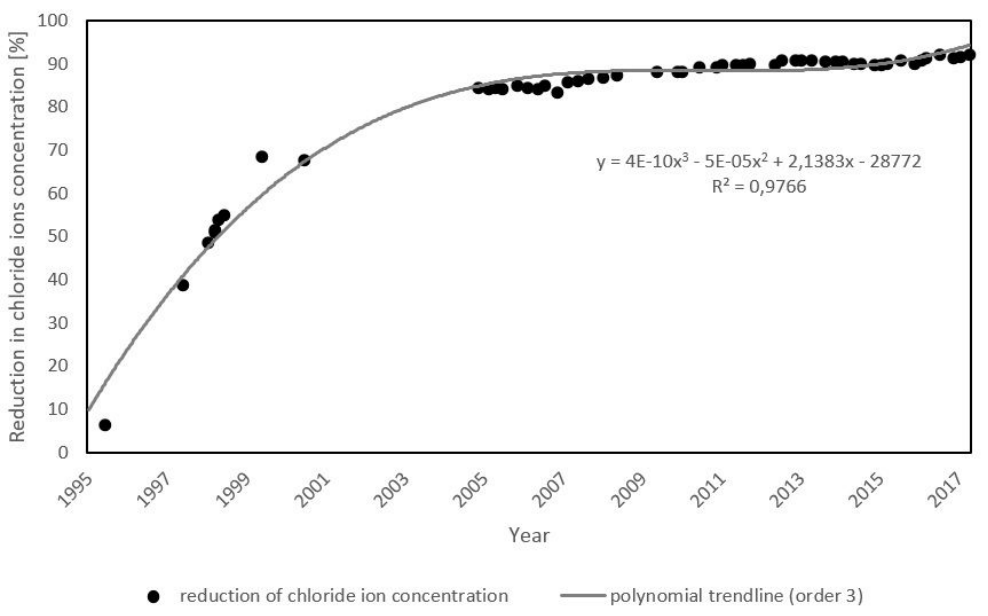

Figure 4. Reduction of chloride ion concentration at point 2

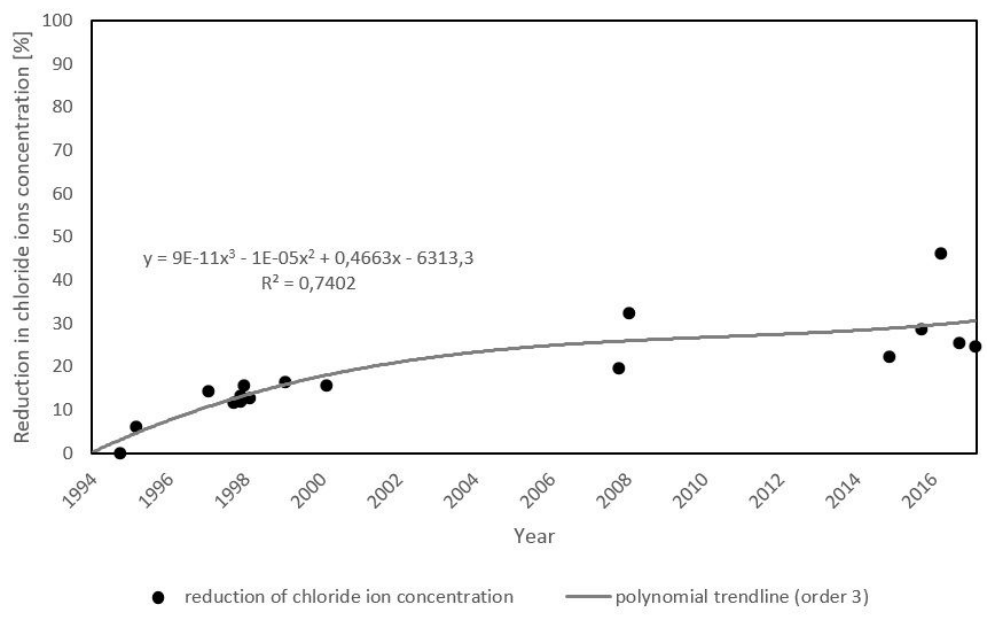

Figure 5. Reduction of chloride ion concentration at point 3

underground water flow from the ponds towards the Noteć river and Słony Rów. The reduction achieved in recent years reaches $30 \%$.

Fluctuations in the reduction of chlorides at point 4 between series are significant; however, there is a clear downward trend (Figure 6). In recent years, the level of chloride ion pollution has decreased by $40 \%$. The coefficient of determination $\mathrm{R}^{2}=0.9294$ indicates a very good model matching [Rabiej 2012], and the trend line suggests further gradual reduction of the pollution level.

The concentration of chloride ions at all described measuring points has decreased since the observation began, which indicates the improvement of the underground water quality in the area of the plant. This is mainly a consequence of the actions that were aimed at reducing the inconvenience of waste to the environment and limiting the release of leachate into waters. These are: launching the process of waste utilization, limiting of its use, sealing and reclamation of sedimentary ponds or construction of drainage barriers.

The pollution accumulated in the soil aeration zone is still an important source of chlorides in water, gradually rinsed with rainwater, infiltrating down the cross profile [Małecki et al. 2016, Wychowaniak and Koda 2014]. It is a process that lasts for many years [Vangelas et al. 2006], but if it happens in such a way as before, the increasingly polluted leaching will have less and less impact on groundwater. A good example of this includes the areas of the former Cracow Soda Works Solvay, which was closed in 1990. According to the studies carried out in 2013, the influence of settlers on the chloride concentration in the Wilga river was significant; however, a reduction in the penetration of ions from settlers into the river along with infiltrating rainwater in comparison to previous years was observed [Gliniak et al. 2014]. 


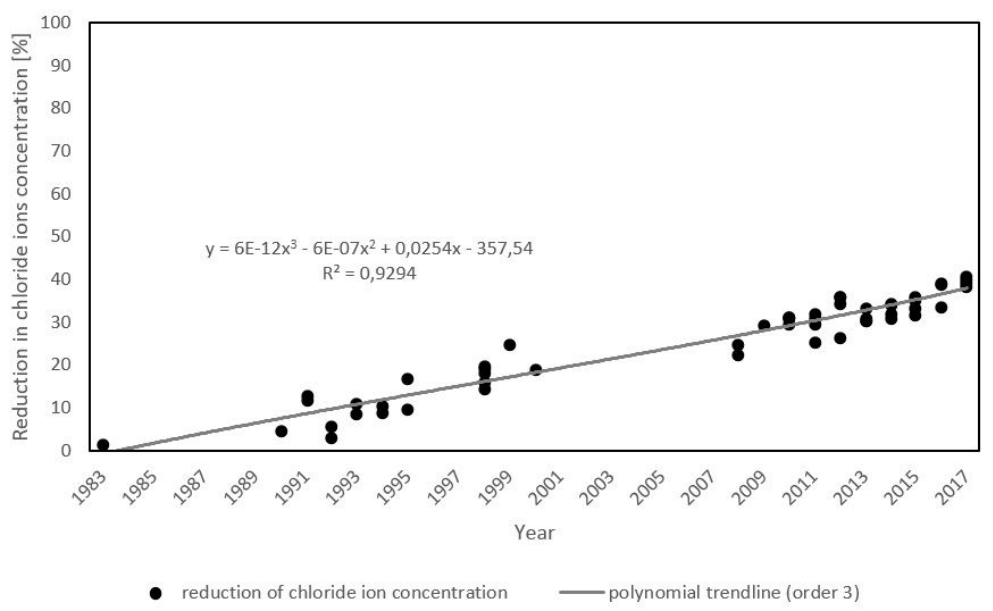

Figure 6. Reduction of chloride ion concentration at point 4.

\section{CONCLUSIONS}

1. On the basis of the analysis of the collected material, the following conclusions were drawn:

2. During the entire measurement period (22-34 years, depending on the piezometer), the concentration of chloride ions at measuring points 1-4 was gradually reduced.

3. Chloride ions concentration shows a decreasing trend in the past years.

4. The protective measures undertaken by the plant were effective in terms of limiting the groundwater pollution.

\section{Acknowledgements}

The research was carried out as part of the work MB/WBiIS/1/2017 and statutory work S/ WBiIŚ/3/2014 and funded by the Ministry of Science and Higher Education.

\section{REFERENCES}

1. Effler S.W., Matthews D.A. 2003. Impacts of a Soda Ash Facility on Onondaga Lake and the Seneca River, NY. Lake and Reservoir Management, 19(4), 285-306.

2. Gliniak M., Pawul M., Sobczyk W. 2014. Impact of the transport and postindustrial landfills of Cracow Soda Works "Solvay" on the status and quality of water in Wilga river in Krakow. Logistyka, 4, 4295-4302. (in Polish)

3. Harat A. Grmela A. 2008. Impact of mine water from The Upper Silesian Coal Basin areas on change quality of water in Olza river in years 2000-2007. Natural Environment Monitoring, 9, 57-62.
4. Kasikowski T., Buczkowski R., Cichosz M. 2008. Utilization of synthetic soda-ash industry by-products. International Journal of Production Economics, 112, 971-984. (in Polish)

5. Kasikowski T., Buczkowski R., Cichosz M., Lemanowska E. 2007. Combined distiller waste utilization and combustion gases desulphurisation method. The case study of soda-ash industry. Resources, Conservation and Recycling, 51, 665-690. (in Polish)

6. Małecki Z.J., Wira J., Moshynsky V., Małecka I. 2016. The threat of worsening the quality of surface and underground waters caused by an unrecultivated waste dumping site in Tłokinia Kościelna near Kalisz. Inżynieria Ekologiczna, 46, 77-87 (in Polish).

7. Matthews D.A., Effler S.W. 2003. Decreases in pollutant from residual soda ash production waste. Water, Air, and Soil Pollution, 146, 55-73.

8. Mosiej J., Komorowski H., Kaczmarczyk A., Suska A. 2007. Effect of pollutants discharged from Łódź conurbation on quality of water in Ner and Warta rivers. ACTA Scientiarum Polonorum, 6(2), 19-30 (in Polish).

9. Pietrucin D., Czop M. 2015. Groundwater contamination by organochlorine compounds in the area of industrial waste dump "Zielona" in Bydgoszcz City. Polish Geological Review 63 (10/2), 997-1001 (in Polish).

10. Policht-Latawiec A., Kanownik W., Łukasik D. 2013. Effect of point source pollution on the san river Water quality San. Infrastructure and Ecology of Rural Areas 1/IV/2013, 253-269 (in Polish).

11. Rabiej M. 2012. Statistic with the Statistica program. Helion, Gliwice.

12. Şener S. 2008. Use of solid wastes of the soda ash plant as an adsorbent for the removal of anionic dyes: Equilibrium and kinetic studies. Chemical Engineering Journal, 138, 207-214. 
13. Siwiec T., Michel M.M., Reczek L. 2016. The influence of aeration on the change of corrosive aggressiveness of groundwater in relation to concrete and steel. Acta Scientiarum Polonorum Architectura, 15 (1), 95-105 (in Polish).

14. Polish Standard PN-EN ISO 5667:2008 Water quality. Sampling.

15. Steinhauser G. 2008. Cleaner production in the Solvay Process: general strategies and recent developments. Journal of Cleaner Production, 16, 833-841.

16. Updated The National Programme for Municipal Waste Water Treatment (NPMWWT) - AKPOŚK 2017 (in Polish).

17. Urbańska J., Urbański K. 2012. Selected Aspects of Reclamation of Soda Waste Landfill Sites.
Geomatics and Environmental Engineering, 6(4), 83-90 (in Polish).

18. Vangelas K.M. Looney B.B., Early T.O., Gilmore T., Chapelle F.H., Adams K.M., Sink C.H. 2006. Monitored natural Attenuation of Clorinated Solvents - Moving beyond reductive dechlorination. Remediation, summer 2006, 5-23.

19. Wiater J. 2011. Influence of municipal landfill site on the ground water quality. Ecological Engineering, 26, 133-146 (in Polish).

20. Wychowaniak D., Koda E. 2014. Assessment of the soil - water system quality in the vicinity of old landfill with a vertical barrier. Remediation, Reclamation and Revitalization. PZITS Oddział Wielkopolski, Poznań (in Polish). 